\title{
THE SMALLEST NON-AUTOGRAPH
}

\author{
BenJAMin S. BAUMER \\ Program in Statistical \& Data Sciences \\ Smith College \\ e-mail: bbaumer@smith.edu \\ YIJIN WEI \\ Department of Mathematics and Statistics \\ Smith College \\ e-mail: ywei@smith.edu
}

AND

Gary S. BloOM

Department of Computer Science

City College

\begin{abstract}
Suppose that $G$ is a simple, vertex-labeled graph and that $S$ is a multiset. Then if there exists a one-to-one mapping between the elements of $S$ and the vertices of $G$, such that edges in $G$ exist if and only if the absolute difference of the corresponding vertex labels exist in $S$, then $G$ is an autograph, and $S$ is a signature for $G$. While it is known that many common families of graphs are autographs, and that infinitely many graphs are not autographs, a non-autograph has never been exhibited. In this paper, we identify the smallest non-autograph: a graph with 6 vertices and 11 edges. Furthermore, we demonstrate that the infinite family of graphs on $n$ vertices consisting of the complement of two non-intersecting cycles contains only non-autographs for $n \geq 8$.
\end{abstract}

Keywords: graph labeling, difference graphs, autographs, monographs.

2010 Mathematics Subject Classification: Primary 05C78; Secondary $05 \mathrm{C} 60$. 


\section{REFERENCES}

[1] G. Bloom and S. Burr, On autographs which are complements of graphs of low degree, Carribean J. Math. 3 (1984) 17-28.

[2] G.S. Bloom, A chronology of the Ringel-Kotzig conjecture and the continuing quest to call all trees graceful, Annals of the New York Academy of Sciences 328 (1979) $32-51$.

doi:10.1111/j.1749-6632.1979.tb17766.x

[3] G.S. Bloom, P. Hell and H. Taylor, Collecting autographs: n-node graphs that have $n$-integer signatures, Annals of the New York Academy of Sciences 319 (1979) 93-102. doi:10.1111/j.1749-6632.1979.tb32778.x

[4] M.R. Garey and D.S. Johnson, Computers and Intractability (W.H. Freeman, New York, 1979).

[5] S. Gervacio, Which wheels are proper autographs, Southeast Asian Bull. Math. 7 (1983) 41-50.

[6] S. Golomb, How to number a graph, Graph Theory Comput. (1972) 23-37.

[7] F. Harary, Sum graphs and difference graphs, Congr. Numer. 72 (1990) 101-108.

[8] S. Hedge and Vasudeva, On mod difference labeling of digraphs, AKCE Int. J. Graphs Comb. 6 (2009) 79-84.

[9] E.M. Luks, Isomorphism of graphs of bounded valence can be tested in polynomial time, J. Comput. System Sci. 25 (1982) 42-65.

doi:10.1016/0022-0000(82)90009-5

[10] A. Rosa, On certain valuations of the vertices of a graph, in: Theory of Graphs, Internat. Symposium, Rome, P. Rosenstiehl (Ed(s)), (New York, Gordon and Breach, 1966) 349-355.

[11] M. Seoud and E. Helmi, On difference graphs, J. Combin. Math. Combin. Comput. 76 (2011) 189.

[12] M. Sonntag, Difference labelling of cacti, Discuss. Math. Graph Theory 23 (2003) $55-65$. doi:10.7151/dmgt.1185

[13] M. Sonntag, Difference labelling of digraphs, Discuss. Math. Graph Theory 24 (2004) 509-527. doi:10.7151/dmgt.1249

[14] K. Sugeng and J. Ryan, On several classes of monographs, Australas. J. Combin. 37 (2007) 277-284.

Received 29 May 2015 Accepted 25 September 2015 